\title{
Monitoring for hydroxychloroquine retinopathy
}

\author{
Andrew Lotery $\mathbb{B}^{1} \cdot$ Mike Burdon ${ }^{2}$
}

Received: 29 January 2020 / Accepted: 29 January 2020 / Published online: 13 February 2020

(c) The Royal College of Ophthalmologists 2020

In this edition of Eye, Yeo et al. investigate how many patients in their area are maintained on hydroxychloroquine 1 year after initiating therapy [1]. Their take home message is of patients starting hydroxychloroquine, $25 \%$ had discontinued by 6 months and 33\% at 12 months. As a result, they suggest timing the baseline retinopathy referral between 6 and 12 months from starting hydroxychloroquine. This is a useful paper and hopefully should help Eye departments to plan their local hydroxychloroquine monitoring services.

Managing the complications of hydroxychloroquine retinopathy is an evolving process driven by research papers such as this. The Royal College of Ophthalmologists has recently developed new guidelines for the monitoring of hydroxychloroquine retinopathy [2]. These were developed in collaboration with colleagues from rheumatology and dermatology after an extensive literature review.

These guidelines were based on evidence that the prevalence of retinopathy in long term use patients appears to be around $7.5 \%$ and depending on dose and duration of therapy can increase to $20-50 \%$ after 20 years of therapy. Risk increases for patients taking more than $5 \mathrm{mg} / \mathrm{kg} /$ day. The retinopathy is manifest as damage to the photoreceptors and subsequent degeneration of the retinal pigment epithelium (RPE). This may produce a "Bull's eye maculopathy" and central visual loss. This is important as the only intervention to prevent further damage is stopping the drug. The risk is increased for patients taking more than $5 \mathrm{mg} / \mathrm{kg} / \mathrm{day}$, those also taking Tamoxifen, and those with renal impairment. In some patients, toxicity may first present as pericentral retinopathy and thus requires screening outside the macula.

The guidelines recommend that all patients planning to take hydroxychloroquine long term i.e. over five years have a

Andrew Lotery

a.j.lotery@soton.ac.uk

Southampton General Hospital, Southampton, UK

2 University Hospitals Birmingham NHS Trust, Birmingham, UK baseline examination in a hospital eye department ideally within six months, but definitely within 12 months, of starting therapy with a colour retinal photograph and spectral domain optical coherence tomography (SD-OCT) scans of the macula. Patients should be referred for annual screening after five years of therapy and be reviewed annually thereafter.

The number of patients taking hydroxychloroquine is increasing and monitoring patients on therapy is challenging in the currently over stretched hospital eye service [3]. A recent paper estimates that 36,444 patients were commenced on HCQ in 2016 with an estimated 166,673 patients already on HCQ [4]. These estimates are higher than in the RCOphth guideline. This analysis captured prescriptions for hydroxychloroquine for any indication, and counted the number of people prescribed hydroxychloroquine rather than only the number of prescriptions. This suggests the burden of monitoring might be higher than previously estimated.

Therefore, it is clear significant extra resources are needed to introduce monitoring of hydroxychloroquine retinopathy into the hospital eye service. The specialities which for good reason initiate a prescription of hydroxychloroquine need to support their colleagues in ophthalmology who are then tasked with monitoring for complications.

Similarly, ophthalmologists need to generate the data to help the guidelines evolve so they are effective but minimise as much as possible the resource impact on ophthalmology departments. To that end, there is currently a BOSU survey of sight loss from hydroxychloroquine usage. It would be useful if ophthalmologists could report all cases of sight loss from hydroxychloroquine use to this survey. In addition, monitoring services should audit their results as this will also inform the true demand for monitoring. The paper by Yeo et al. in this edition of Eye is a good example of how useful data can be generated.

Unfortunately, hydroxychloroquine monitoring while challenging is the only solution to prevent progressive and irreversible sight loss [5, 6]. Similar conclusions and recommendations have been made by the American Academy of Ophthalmology [7]. 


\section{Compliance with ethical standards}

Conflict of interest AL-former Chair of the Royal College of Ophthalmologists hydroxychloroquine guidelines committee and chair of the Royal College of Ophthalmologists Scientific committee. MBformer member of the Royal College of Ophthalmologists hydroxychloroquine guidelines committee and President of the Royal College of Ophthalmologists.

Publisher's note Springer Nature remains neutral with regard to jurisdictional claims in published maps and institutional affiliations.

\section{References}

1. Yeo B, Hamad R, Paul A, Low A. Hydroxychloroquine baseline retinopathy screening: when to refer patients? A practical approach to optimise resource use. Eye (Lond). 2020. https://doi.org/10. 1038/s41433-020-0794-3.
2. RCOphth. Hydroxychloroquine guidelines. 2018. https://www. rcophth.ac.uk/standards-publications-research/clinical-guidelines/.

3. RCOphth. The way forward. 2017. https://www.rcophth.ac.uk/sta ndards-publications-research/the-way-forward/.

4. Pearce FA, Grainge MJ, King AJ, Lanyon PC. Implementing screening for hydroxychloroquine ocular toxicity: how big is the problem? Epidemiology of hydroxychloroquine prescriptions in the UK Clinical Practice Research Datalink. Rheumatology. 2019;58 (Supplement_3):kez105.037.

5. Marmor MF, Hu J. Effect of disease stage on progression of hydroxychloroquine retinopathy. JAMA Ophthalmol. 2014;132: 1105-12.

6. Pham BH, Marmor MF. Sequential changes in hydroxychloroquine retinopathy up to 20 years after stopping the drug: Implications for Mild Versus Severe Toxicity. Retina. 2019;39: 492-501.

7. Marmor MF, Kellner U, Lai TY, Melles RB, Mieler WF. American Academy of Ophthalmology. Recommendations on Screening for Chloroquine and Hydroxychloroquine Retinopathy (2016 Revision). Ophthalmology. 2016;123:1386-94. 